\title{
Регистрация сигналов акустической эмиссии в композитных материалах волоконно-оптическими датчиками на основе ФС-лазерной записи
}

\author{
$\underline{\text { В.С. Терентьев }}^{1, *}$, А.В. Достовалов ${ }^{1}$, А.Н. Серьёзнов ${ }^{2}$, А.Б. Кузнецов ${ }^{2}$, \\ В.А. Симонов ${ }^{1}$, А.А. Вольф ${ }^{1}$, М. И. Скворцов ${ }^{1}$, С.А. Бабин ${ }^{1}$ \\ ${ }^{1}$ Институт автоматики и электрометрии СО РАН \\ ${ }^{2}$ Сибирский научно-исследовательский институт авиаџии имени С.А. Чапльгина \\ *E-mail: terentyev@iae.nsk.su
}

DOI: 10.31868/RFL2020.205-206

Создание компактных датчиков регистрации сигналов акустической эмиссии (АЭ) является важной задачей в области разработки полимерных композитных материалов (ПКМ), подверженных высоким эксплуатационным нагрузкам, что особенно актуально в авиастроении, где элементы конструкций из композитных материалов должны регулярно тестироваться на наличие микродефектов и трещин, которые значительно снижают прочностные характеристики композитного материала [1]. Данные датчики, интегрированные в композитный материал, должны регистрировать сигналы АЭ, возникающие в процессе микроразрушений, разрыва полимерных волокон композитного материала, и, таким образом, регистрировать данные события и сигнализировать о состоянии композитного материала. Волоконо-оптические датчики (ВОД) являются наиболее перспективным типом датчиков АЭ для применений в композитных материалах, поскольку они имеют малые габариты и вес по сравнению с тензодатчиками, что облегчает их интегрирование в структуру материала и позволяет размещать большое кол-во датчиков в одном измерительном канале [2]. Технология фс лазерной записи волоконных брэгговских решеток (ВБР) дает дополнительные преимущества при создании чувствительных элементов датчиков АЭ, поскольку позволяет проводить запись ВБР через защитное полиимидное покрытие, что существенно увеличивает прочностные характеристики датчика, а также расширяет рабочий температурный диапазон [3].

В данной работе представлены результаты по регистрации сигналов АЭ с помощью волоконно-оптических датчиков на основе интерферометра ФабриПеро (ИФП), состоящего из двух слабоотражающих ВБР, записанных фс лазерным излучением в волокне с полиимидным покрытием. Были проведены эксперименты по оптимизации базы интерферометра для повышения чувствительности измерений. Схема опроса ВБР ИФП основана на регистрации отраженного от интерферометра узкополосного сигнала и регистрации изменений данного сигнала вследствие акустических воздействий на ИФП. Регистрация сигнала АЭ осуществлялась в процессе растяжения с помощью гидравлической разрывной машины MTS-100 образца ПКМ прямоугольной формы с закрепленными на нем ВОД и пьезодатчиками типа ПК-02-05 (рис. 1a). На рис. 16 представлены сигналы АЭ, регистрируемые с помощью ВОД и пьезодатчика в процессе разрушения композитного образца. Хотя ВОД обладают в 10 раз меньшей чувствительностью по сравнению с пьезоэлектрическими датчиками, проведенные эксперименты показали возможность использования ВОД для регистрации АЭ в процессе разрушения композитного материала. 

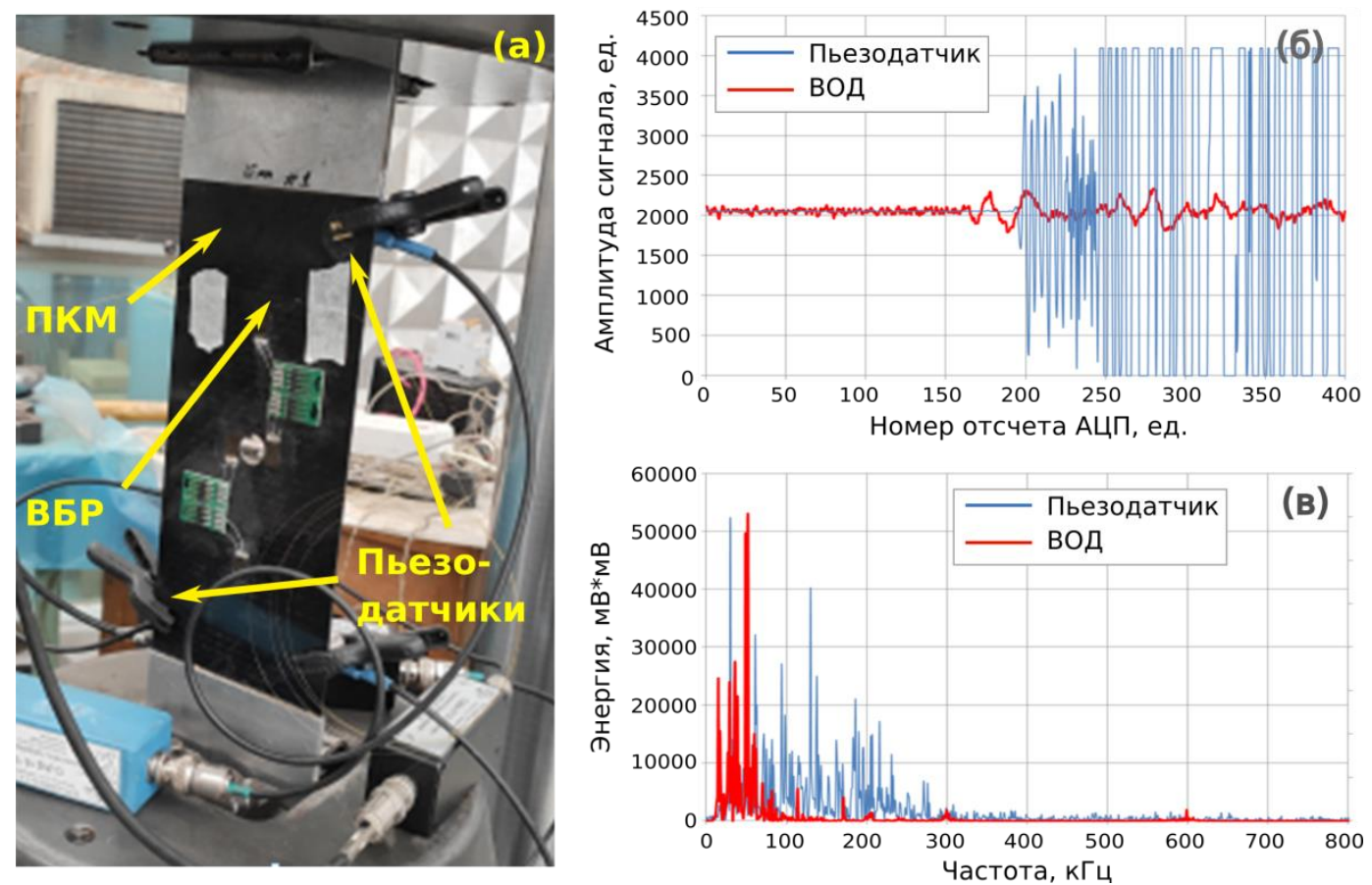

Рис. 1. а) Образец ПКМ с ВОД и пьезодатчиками в гидравлической разрывной машине MTS-100, б) Форма сигнала, регистрируемая в процессе разрушения композитного образца материала, для ВОД и пьезодатчика, в) Форма спектра сигнала регистрируемые в процессе разрушения композитного образца материала для ВОД и пьезодатчика.

\section{Литература}

[1] H. Song et al., Proc. 2011 IEEE 5th Int. Conf. Cybern. Intell. Syst. CIS 2011, 52 (2011)

[2] Z. Ma, X. Chen, Sensors, 19, 55 (2019)

[3] A. V. Dostovalov et al., Opt. Express 24, 16232 (2016) 